\title{
Health management
}

\author{
Efficient people are the laziest, but they are brilliant lazy people.
}

(David Dunham)

\section{Roxana Chiriță, Elena-Rodica Popescu}

Roxana Chiriță - Professor, M.D., Ph.D., senior psychiatrist, "Grigore T. Popa” University of Medicine and Pharmacy, Iași, "Socola” Institute of Psychiatry Iaşi

Elena-Rodica Popescu - M.D., Ph.D. student, psychiatrist, assistant professor, "Grigore T. Popa" University of Medicine and Pharmacy, Iaşi, "Socola” Institute of Psychiatry Iași

Society is in continuous development and adaptation in all fields of activity, especially in the medical area, necessary to improve the quality of life. World Health Organization defines this small discipline, Public Health, the science and art of disease prevention, prolongation of life, and health promotion through the organized efforts of society to which can be added the improvement of notions of biostatistics, epidemiology over well-acquired knowledge of general medicine. All this with the aim of a good quality of life for all people, whether they are providers or providers of health services or simple beneficiaries of health services, the role and function being interchangeable.

The basic concepts of management were described in different ways for thousands of years. The first reference to management was found in the Old Testament of the Christian Bible. Some practical managerial concepts are still described today in the construction of the pyramids of Ancient Egypt; suggestions of good management can be found in the Code of Good Manners of Babylon, 3000 years ago.

Social Medicine was established for the first time in Bucharest under the leadership of Prof. Gh. Banu in 1942. In 1948, the discipline Sanitary Organization was selected for the first time in Iași, led by lecturer Dr. Ion Spinu, and currently, this discipline is called Public Health and Sanitary Management.

The specialty of Public Health and Sanitary Management is included in the terminology of medical things. The establishment of this specialization initially conceived as a 
.

discipline that would come to the aid of young doctors as a necessity of literacy in the integral medical field. For a start so that later it could be known, in the true sense of the word management, which includes the main management areas at the level of a hospital and the main management activities.

In general terms, management is a process by which work is done through others done on time and within budget, involves a series of integrated activities. Management determines a combination of means (financial-budget, human-human resource, materials) to generate socially helpful services.

The basic terms that revolve around management are effectiveness and efficiency, precisely in this order, which involves the availability of primary conceptual skills, human skills, technical skills (medical, financial, and legislative knowledge), and adaptation to change. Conceptual skills and transformation to change present together lead to good management. Change is understood as a continuous confrontation, identification, evaluation, and action determined mainly by political factors, political legislation, the government's economic policy or other countries, international regulations, wars, trade union activity, technological factors, and socio-cultural factors.

Isn't $t$ it funny how day by day nothing changes, but when you look back, everything is different.

A good organization of the entire medical system can prevent us from attributing the above expression.
Healthcare managers oversee financial initiatives; the economic field is a vital aspect of the hospital unit, designs and analyzes, evaluates, communicates, and reviews financial strategies, and recruits the appropriate human resource for the crew.

It also plays a bridge role, a link between doctors and other heads of health units, both territorial, inside the borders or outside them. All of the above require extraordinary communication skills at all hierarchical levels, of all types (internal, external), with the transmission of clear, consistent information in and for the benefit of the health unit. At the same time, managers need to ensure the quality-of-care standards that govern all facilities in the medical industry.

The biggest challenge for a hospital manager is to do things consistently and correctly every time.

We conclude by saying that a manager or management is something or someone who makes the resources of a health unit turn into results by focusing on the beneficiary of health services (patient), continuous quality improvement, teamwork. 